\title{
Eliciting Salient Factors in Online Shopping Behavior Research
}

\author{
Laila Refiana Said ${ }^{*}$ \\ Faculty of Economics and Business, Universitas Lambung Mangkurat, Indonesia
}

\begin{abstract}
This paper argues the importance of an exploratory study prior to hypotheses testing in any causal-effect or explanatory predictive behavioral research. It proposes a stage of eliciting salient factors using a framework from theory of planned behavior. The paper opted for an exploratory study by firstly examining 12 academic research of online shopping behavior in Indonesia. Secondly, using the openended questions given to 30 respondents, the paper explored reasons respondents shop or not shop online. Those immediate responses were documented and termed as salient factors. Thirdly, the salient factors were then combined with foregone factors based on literature reviews. The final set of factors was chosen as predictive variables in order to provide more accurate potential antecedents for predicting and explaining online shopping behavior. The paper provides sound and practical guidance in eliciting salient factors and formulating a final set of factors in causal-effect/explanatory predictive behavioral research on online shopping behavior. It suggests that academic research should place importance on the stage of eliciting salient factors. Foregone factors are used to strengthen the choice of predictive variables. Both salient and foregone factors are necessary for the final set of factors in such online shopping behavior studies. The paper includes implications for the online vendors and government agencies to promote ecommerce. This paper fulfils a need to conduct exploratory study on online shopping behavior to understand such phenomenon of high internet penetration yet low rate of online buying behavior by focusing on salient factors of the studies.
\end{abstract}

Keywords: E-commerce, online shop, salient factors, theory of planned behavior

\section{Introduction}

Nowadays when we discuss about social change, we cannot escape from the issue of digitalization of the world with the increasingly widespread internet penetration in many countries. The Internet is recognized as a tool for social change (Jiménez, 2001). The present generation is what people called as the "Net Generation". The internet is viewed useful as it makes everyday life more efficient. The internet can save time, make people more productive because many things can be done online (e.g. banking, shopping, research literature), and with the increase of social media we even have more socializing online (DiMaggio et al., 2001).

Internet penetration in ASEAN, especially in Indonesia, is growing very fast. Internet users in Indonesia per April 2016 had reached 132.7 million, which has grown rapidly compared to 2014 with only about 88 million internet users (APJII, 2016). Based on the most recent survey by APJII in 2016, most Internet users in Indonesia are aged 35-44 years (29.2\%), followed by users aged 55 years and over (10\%). While the number of internet users in Indonesia has been growing rapidly from year to year and the e-commerce market of Indonesia is predicted to be the largest in Southeast Asia (Marketplus, 2016), the reality is that few Indonesian consumers are taking advantage of their access to online

\footnotetext{
* Corresponding author at Jalan Brigjen H. Hasan Basri, Pangeran, Kec. Banjarmasin Utara, Kota Banjarmasin, Kalimantan Selatan 70123, Indonesia. Email: lrsaid@unlam.co.id
} 
shopping. APJII (2016) illustrates that 82.2 million or $62 \%$ of internet users have visited an online shop. However, referring to a survey conducted by International Data Corporation (IDC), only $13.3 \%$ of Internet users in Indonesia buy goods over the internet (Ngazis and Angelia, 2016). The rest mostly use the internet for other activities, such as accessing email, accessing entertainment websites, accessing social media sites, accessing news, professional networking, and online games (Ngazis and Angelia, 2016).

Various surveys have produced many contradictory results. Even some surveys reported that a very impressive number of between 50 and 70 percent of Internet users in Indonesia have shopped online (Ngazis and Angelia, 2016). The Government of Indonesia has predicted a growth number of online shopping along with the increase of smartphone and internet users. According to APJII (2016), around 63.1 million or about $47.6 \%$ of internet users in Indonesia use mobile devices (smartphones). The Government of Indonesia, through the 14th Economic Policy Package, has also targeted ecommerce transactions to penetrate US\$ 130 billion by the year 2020. However, the demographics of consumers who shop online in Indonesia are still dominated by people living in big cities, especially in Jakarta as the capital city of the country. In fact, increasing use of smartphones and the internet has not increased online shopping (Ngazis and Angelia, 2016).

\section{Problem Description}

What causes the reluctance of Indonesian internet users to make online purchases? Why do academics fail to understand the market and consumer behavior of online shopping? To understand the emerging internet penetration yet low power of online buying in Indonesia, this paper examines the stages of antecedents' selection in the academic research of online shopping behavior.

By using Google search engine in order to analyze academic research of online shopping behavior in Indonesia, 3 key words were searched for in Indonesian language only: (1) influence; (2) purchase; (3) online. 1,330,000 results were found in 0.51 seconds using those three keywords. From among all those results, a sample was taken consisting of 12 academic research journals and unpublished theses as shown in Table 1. All antecedents in those 12 researches were selected based merely on literature reviews. All sample research had regression analysis using a variety of statistical packages such as SPSS, AMOS, and PLS, and there were many similar predictor variables choices as they were mostly replicative studies. There were no reports of exploratory research prior to testing the hypotheses.

After reviewing all sample research, no eliciting salient factors were found prior to formulating antecedent variables for the models in those causal effect research. Those researchers tended to choose antecedent variables based on previous research (foregone factors) only. In this case, the antecedents might not necessarily reflect the actual predictors of online shopping behavior in Indonesia. Thus, academic research might fail to give meaning or to predict accurately because they focus too much on the quantitative regression analysis and testing the hypotheses. The process of determining antecedents of online shopping behavior were not through comprehensive explorative studies.

This paper argues that it is necessary to perform a more comprehensive method of research that begins by identifying salient factors before determining antecedents of online shopping behavior. It will provide more accurate potential antecedents for predicting and explaining online shopping behavior. The stages in theory of planned behavior (Ajzen, 1985, 1988) are taken as the basis in the filing of the prediction of online shopping prediction research stages because the theory of planned behavior (TPB) is seen as careful but practical in the process of selecting predictors in behavioral analysis research. This paper illustrates a detailed eliciting stage of salient factors prior to hypotheses testing of online shopping behavior.

\section{Review of Literature}

This sections contains the method that author use to test the hypothesis or issue. In this section author should be able to explain the sample they use, each variable used in the study as well as its measurements, the questionnaire (if any), econometrics model, and research model.

\section{Theory of Planned Behavior (TPB)}

According to the Oxford English dictionary, 'salient' means the most noticeable or important. Its synonyms include words such as important, main, principal, major, chief, primary, notable, noticeable, noteworthy, dominant, key, crucial, vital, essential, pivotal, prime, and central. The theory of planned 
behavior urges the importance of conducting an elicitation stage to determine the final sets of salient beliefs.

As shown in Figure 1, someone's behavior is influenced by someone's intention to conduct that particular behavior. According to TPB, an intention is influenced by attitude, subjective norm, and perceived behavioral control (Ajzen, 1988). An attitude is someone's evaluation toward a symbol, object or aspect in a favorable or unfavorable manner, while subjective norm deals with perceived normative prescription (Ajzen, 1988). The other antecedent of intention in TPB is 'perceived behavioral control', which is someone's generalized belief that he/she has the power/control to do or not do a particular behavior.

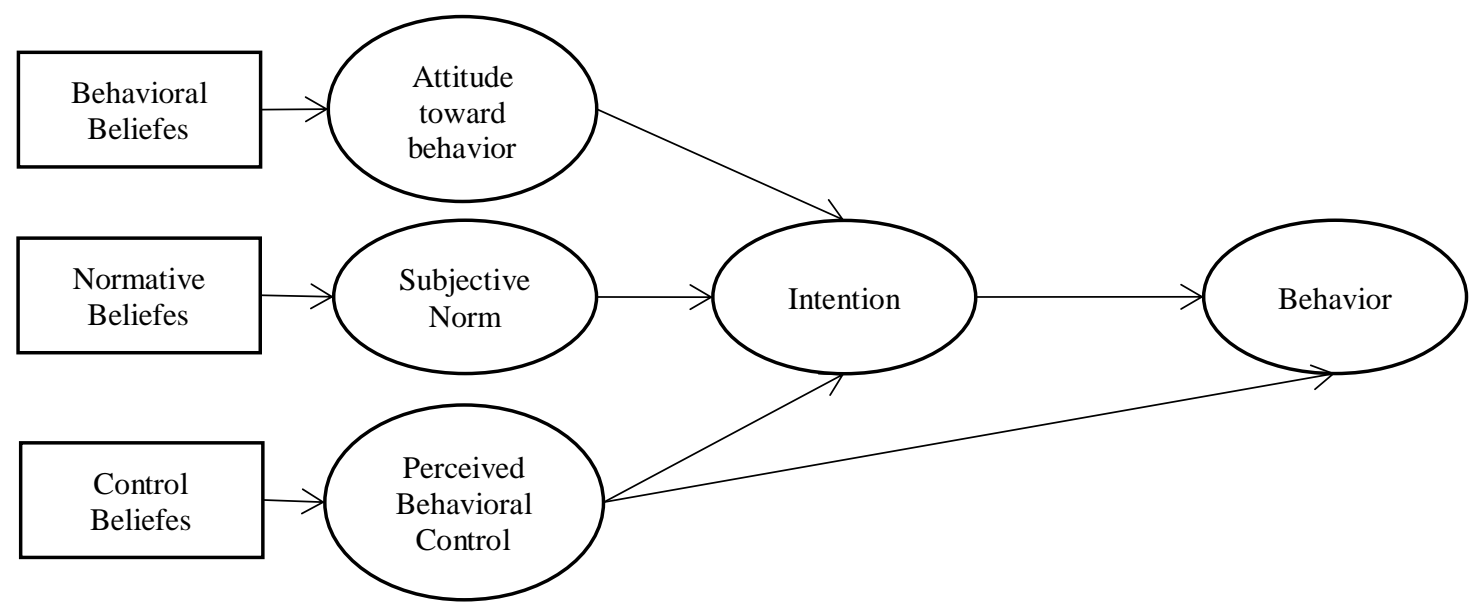

Figure 1. Theory of Planned Behavior (TPB)

In TPB, salient beliefs are the answers that come from immediate responses from respondents: "What do you think would be the advantages for you to engage in ... (certain behavior)"? (Herath, 2010). That open-ended question is given to a sample being studied. Ajzen and Fishbein (1980) have proposed a guidance of salient beliefs elicitation procedure prior to the main explanatory predictive study as follows, take account of 10 or 12 most answers, take account the answers that exceed a certain incidence. For instance, all answers indicated by at least $10 \%$ of the sample, take as many answers as required to represent a certain percentage (e.g. $75 \%$ ) of all answers. Those answers, as we refer them as beliefs, then will be used in the model of TPB (Francis et al., 2004).

According to Herath (2010), eliciting salient beliefs are crucial to be applied in any causal-effect or explanatory predictive behavioral studies, not only in the theory of planned behavior. Thus, this paper intends to elicit salient beliefs by applying the procedure from theory of planned behavior as a framework of study. Since eliciting salient beliefs are important to any causal-effect or explanatory predictive behavioral study, this paper will use the term 'salient factors' instead of salient beliefs because a 'factor' means aspect, fact, or influence that contributes to a result or outcome. It is in a more general form, thus the term salient factors can be applied to any model of causal effect studies instead of the particular theory of planned behavior model.

\section{Proposed Method}

In order to effectively predict behavior in causal-effect/explanatory research, it is necessary to perform a prior qualitative study. That qualitative study is used to determine a set of predictive variables of a particular behavior. This paper proposes the following elicitation stages to be carried out, identify 'foregone factors' based on references/literatures of similar studies, elicit 'salient factors', formulate antecedents based on salient and foregone factors, model the causal-effect/explanatory predictive behavior research. 


\section{Identifying 'foregone factors' based on references/literatures of similar studies}

Identifying foregone factors based on previous studies relating to our study is important in order to obtain a mental picture of the object being studied. For the case of predicting online buying behavior, it is recommended to examine surveys from technology market research agencies or organizations relating to online studies. For instance, International Data Corporation (IDC) has some exploratory questions regarding online buying behavior, such as "What drives you from purchasing online?" and "What hinders you from purchasing online?" (Ngazis and Angelia, 2016).

Based on such explorative questions, Ngazis and Angelia (2016) found that the causes of the widespread demographics of online shopping in Indonesia are the lack of trust in online shopping, lack of credit card use and lack of education of people outside Jakarta, the nation's capital. More than 50\% of consumers still prefer to feel and touch the product to be purchased. This low percentage is influenced by the habits of Indonesian consumers who still love to shop in physical stores. From the analysis, it revealed that $68.5 \%$ of people were reluctant to buy online because the product could not be seen physically while $57.7 \%$ argued that the product information listed was not so clear. Consumers are still less convinced by the payment method offered by a number of online trading sites. So it is with those who are afraid of online fraud, while the main reasons Indonesia consumers shop online were due to flexible shopping time and various interesting promotions (Ngazis and Angelia, 2016).

\section{Eliciting 'Salient Factors'}

Researched found that the salient beliefs elicited by affective-response questions (like or dislike, love or hate etc.) had a different final set of salient beliefs than that of the instrumental-response questions (advantages or disadvantages of an object). According to researched, it is better to ask respondents to state their own beliefs. Therefore, to elicit 'salient factors' of online shopping behavior, this study did an exploratory survey by asking 30 respondents these open-ended questions from a target population of college students: "What makes you want to purchase online?" and "What makes you not want to purchase online?". Open-ended responses are valuable in an exploratory research prior to a causal-effect or explanatory predictive study. This argument is also strengthened by (Schoon, 1998) who encouraged using open-ended questions to elicit the salient factors of the research object.

According to Herath (2010), there are two ways to elicit salient beliefs in the theory of planned behavior (TPB). First, all answers from such open questions can be considered as a final set of salient beliefs. Second, only frequent answers should be used as a final set of salient beliefs in the study Herath (2010).

Since there were only 30 respondents, this paper suggests using all answers regarding reasons why they shop or do not shop online as salient factors in a study of online shopping behavior. The salient factors will then be cross examined with foregone factors. The salient factors found in this study are described in Table 2.

Table 2. Reasons for purchase / not purchase online

\begin{tabular}{|c|c|c|c|c|}
\hline No. & Factors & $\begin{array}{l}\text { Number of } \\
\text { response }(\%)\end{array}$ & Purchase online & Not purchase online \\
\hline 1. & Trust & $8(26.7 \%)$ & & $\begin{array}{l}\text { I do not trust; } \\
\text { Actual product is very different with } \\
\text { the ad image; } \\
\text { Do not trust the courier; } \\
\text { Many scams }\end{array}$ \\
\hline 2. & Time efficiency & $6(20 \%)$ & Saving time & \\
\hline 3. & Price & $6(20 \%)$ & Cheaper & $\begin{array}{l}\text { Sometimes postage is more expensive } \\
\text { than the goods }\end{array}$ \\
\hline 4. & Attitude & $5(16.7 \%)$ & $\begin{array}{l}\text { Fun; } \\
\text { Easy }\end{array}$ & $\begin{array}{l}\text { It seems difficult, complicated; } \\
\text { Prefer to see the goods physically }\end{array}$ \\
\hline 5. & Risk & $3(10 \%)$ & & $\begin{array}{l}\text { Goods do not arrive on time; } \\
\text { Goods do not arrive at all; } \\
\text { Damaged goods }\end{array}$ \\
\hline 6. & Payment & $1(3.3 \%)$ & & Complicated payment method \\
\hline 7. & Communication & $1(3.3 \%)$ & & Do not want to chat with the seller \\
\hline
\end{tabular}




\section{Formulating antecedents based on salient and foregone factors}

Both salient and foregone beliefs are necessary for the final set of beliefs in the theory of planned behavior Herath (2010). This paper examines the factors elicited by open-ended questions designed to prompt salient factors, and compare these with the foregone factors. Table 3 describes factors of online shopping behavior which belong to salient and/or foregone factors. The factors will become possible antecedents in predicting online shopping behavior.

Table 3. Salient and Foregone Factors of Online Shopping Behavior

\begin{tabular}{clccc}
\hline No. & \multicolumn{1}{c}{ Factors } & Salient & & Foregone \\
\hline 1. & Trust & $\sqrt{ }$ & $\sqrt{ }$ & \\
2. & Perceived risk & $\sqrt{ }$ & $\sqrt{ }$ & \\
3. & Perceived ease of use & $\sqrt{ }$ & $\sqrt{ }$ & \\
4. & Price & $\sqrt{ }$ & $\sqrt{ }$ & \\
5. & Convenience & $\sqrt{ }$ & $\sqrt{ }$ & \\
6. & Customer service & $\sqrt{ }$ & $\sqrt{ }$ & \\
7. & Attitude & $\sqrt{ }$ & $\sqrt{ }$ & \\
8. & Product availability & - & & $\sqrt{ }$ \\
9. & Product variety & - & & \\
10 & Promotion for online shop & - & & \\
\hline
\end{tabular}

\section{Modeling the causal-effect/explanatory predictive behavior research}

Based on both prior exploratory study by eliciting the salient factors and literature reviews for choosing foregone factors, researchers may draw some appropriate research models. This paper gives two examples of possible research models as shown in Figure 2 and Figure 3. In Figure 2, all factors becomes antecedents of online shopping behavior, while Figure 3 illustrates a more complex model of antecedents of online shopping behavior. Both sample models are explained in the discussion section.

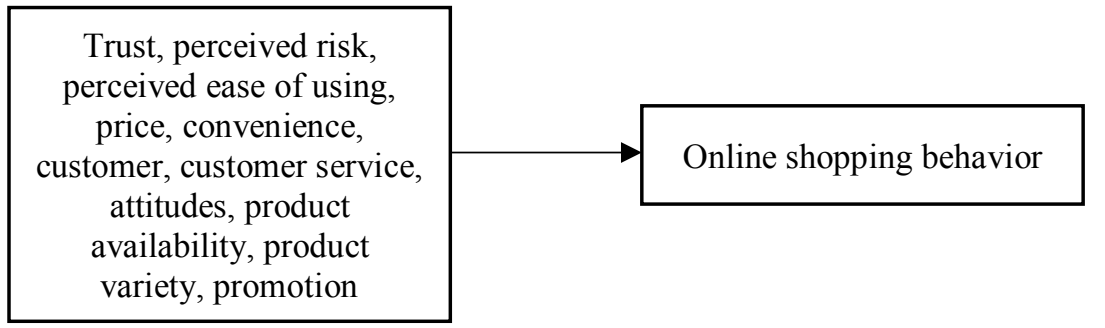

Figure 2. Hypotheses model 1

Trust, perceived risk, perceived ease of using, price, convenience, customer, customer service, product availability, product variety, promotion

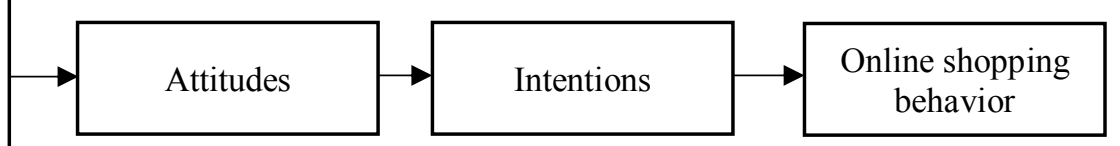

Figure 3. Hypotheses model 2

\section{Discussion}

Both salient and foregone factors are used in Hypotheses Model 1 and Model 2. For hypotheses model 1 (Figure 2), all factors hypothesized directly influence online shopping behavior. This is a very simple/basic model to explain online shopping behavior based on the prior exploratory studies. Researchers may further analyse those antecedents by conducting factor analysis statistical method to reduce numbers of antecedents and categorize them into several common factors. 
Attitude has two aspects, i.e. affective and cognitive. Based on the Theory of Reasoned Action Ajzen and Fishbein (1980, 2000) and the Theory of Planned Behavior (Ajzen, 1985, 1991), salient behavioral beliefs determine attitude towards a particular behavior. In Model 2 (Figure 3), all factors (excluding attitude) have arrows pointing to attitude. Attitude is regarded as an antecedent of intention to shop online and that intention influences online shopping behavior (see Theory of Reasoned Action and Theory of Planed Behavior).

All models are acceptable as long as they have adequate supporting theories. Those two examples are merely used in this paper as an illustration of applying salient and foregone factors in explanatory predictive behavior research, such as online shopping behavior. More complex models can be drawn for hypotheses testing.

To understand such phenomenon of high internet penetration yet low online shopping behavior, salient factors of online shopping behavior need to be focused on. A careful selection of possible predictors of online shopping behavior may be helpful to clearly view what makes people eager or reluctant to shop. For example, 'trust' is still a big issue perceived by Indonesian consumers to shop online. Therefore, vendors should guarantee the security of payment method, safe courier, guarantee the product quality in order to gain trust from their customers. Furthermore, there should be a government agency to protect consumer rights regarding this online trade. The government agency will actively encourage online businesses to have a relationship rather than merely one-time transaction with their customers. Good law enforcement is also required to prevent fraud in online trading. Moreover, potential consumers may be gained when online businesses actively promote their websites.

\section{Conclusion}

It is necessary to conduct an elicitation study thoroughly to choose salient factors in causal-effect or explanatory predictive studies. This paper provides direction to conduct a qualitative study prior to causal-effect or explanatory predictive studies using a framework from Theory of Planned Behavior. The stages of eliciting salient beliefs from the Theory of Planned Behavior are recommended since the theory has been used widely in explanatory predictive behavioral research. Academic research should place importance on the stage of eliciting salient factors. Foregone factors are used to strengthen the choice of predictive variables. Both salient and foregone factors are necessary for the final set of factor in such online shopping behavior studies.

\section{References}

Ajzen, I. (1985), "From intentions to actions: a theory of planned behaviour", Action Control: From Cognition to Behavior, pp. 11-39.

Ajzen, I. (1988), Attitudes, Personality, and Behavior, The Dorsey Press, Chicago.

Ajzen, I. (1991), "The theory of planned behavior", Organizational Behavior and Human Decision Processes, Vol. 50, pp. 179-211.

Ajzen, I. and Fishbein, M. (1980), Understanding Attitudes and Predicting Social Behavior, Prentice-Hall, Englewood Cliffs, NJ.

Ajzen, I. and Fishbein, M. (200o), "Attitudes and the attitude-behavior relation: reasoned and automatic processes", European Review of Social Psychology, Vol. 11, pp. 1-33.

APJII. (2016), "The penetration and behavior of Indonesia internet users", Asosiasi Penyelenggara Jasa Internet Indonesia.

DiMaggio, P., Hargittai, E., Neuman, W.. and Robinson, J.. (2001), "Social implications of the internet", Annu. Rev. Sociol, Vol. 27, pp. 307-36o.

Francis, J.., Eccles, M.P., Johnston, M., Walker, A., Grimshaw, J., Foy, R., Kaner, E.F.S., et al. (2004), Constructing Questionnaires Based on the Theory of Planned Behavior: A Manual for Health Services Researches, Newcastle upon Tyne: Centre for Health Services Research.

Herath, C.. (2010), "Eliciting salient beliefs are critical to predict behavioural change in theory of planned behavior", Psychologie.

Jiménez, K.. (2001), “The internet: a tool for social change?; Elements of a necessary discussion”, Evaluation of the Social Impact of the Internet in Central America: The Case of Civil Society Organizations.

Marketplus. (2016), "Pasar e-commerce Indonesia diprediksi bakal terbesar di Asia Tenggara".

Ngazis, A.. and Angelia, M. (2016), "IDC: hanya 13,3 persen netizen Indonesia yang belanja online; Masih ada kendala penetrasi belanja online ke area luar Jakarta".

Schoon, I. (1998), “Questionnaire Design”, in Nunn, J. (Ed.), Laboratory Psychology; A Beginner's Guide, Psychology Press Ltd, East Sussex, UK. 